\title{
A multispecies, multiscale analysis of spatial pattern and its application to a shallow-water gorgonian community
}

\author{
Paul M. Yoshioka, Beverly Buchanan Yoshioka \\ Department of Marine Sciences, University of Puerto Rico, Mayaguez, Puerto Rico 00709, USA
}

\begin{abstract}
We describe a multispecies, multiscale analysis of spatial pattern, called a 'Community Mosaic Analysis', and apply the technique to 2 shallow-water gorgonian communities in Puerto Rico. Spatial patterns were similar at both sites examined. Gorgonian colonies occurred at predominant mosaic scales (patch sizes) of about $1 / 4$ and $2 \mathrm{~m}^{2}$ Gorgonian species were positively associated (cooccurred) at these and all smaller $\left(<1 \mathrm{~m}^{2}\right)$ spatial scales investigated. These results indicate that gorgonian species are affected similarly by small-scale features of their habitat. No instances of significant negative associations among species were noted, suggesting that competition for spatial resources does not play a dominant role in the ecology of shallow-water gorgonian communities.
\end{abstract}

\section{INTRODUCTION}

Spatial patterns reflect the net effect of various physical and biological factors affecting the birth, death (and movement) of individuals in single species populations (e.g. Hutchinson 1953). As a consequence, numerous techniques have been developed for the analysis of dispersion patterns (reviewed by Grieg-Smith 1983) which, in turn, are often used to infer the identity of important population processes. By extension, we believe that environmental factors structuring communities are reflected in multispecies patterns, and that the examination of such patterns should provide important insights into the nature of community-level mechanisms. Unfortunately, with the exception of a few notable examples (Jumars 1975a, b, Hubbell 1979), few studies have been conducted on spatial patterns of natural communities; undoubtedly because appropriate analytical methods are generally undeveloped. For instance, 'nearest neighbor' techniques for the description of multispecies associations would require the tedious compilation of all pairwise, species-species patterns (e.g. Diggle 1983).

In this report we introduce a 'Community Mosaic Analysis' which is capable of describing patterns of multispecies associations at a variety of spatial scales. We then apply the technique to 2 shallow-water gorgo- nian communities in Puerto Rico and draw inferences about underlying causal mechanisms.

The utility of a community-level approach in studies of spatial pattern can be justified on several grounds. First, both field and theoretical ecologists have recently recognized the importance of spatial heterogeneity in the dynamics of natural communities (e.g. Dayton et al. 1984, DeAngelis \& Waterhouse 1987). Secondly, major conceptual models have already produced contrasting predictions of spatial pattern which can be tested (falsified) given the availability of relevant methodologies. For instance, resource partitioning theory predicts that competing species will specialize in different habitat types (Schoener 1974), thereby resulting in a negative association among species at the appropriate habitat scale' (MacArthur 1972). Alternatively, some variants of the 'lottery' model of recruitment (Sale 1977) predict a random association among species. Finally, the associational defense scenario of Hay (1986), wherein chemically-defended species provide spatial refuges from predation for vulnerable species, predicts a positive association among species on small spatial scales.

Our choice of the shallow-water gorgonians as a model system was largely dictated by the belief that spatial pattern may be especially critical for gorgonians (or other sessile communities) because the effects of competition (Dana 1976, Jackson 1979), predation (Litt- 
ler et al. 1987), disturbance (Woodley et al. 1981), and other ecological processes may be mediated by spatial relationships among organisms. In addition, habitat space per se is often acknowledged to be a major limiting resource in sessile coral reef communities (Jackson 1977, Connell 1978).

\section{METHODS}

Community Mosaic Analysis. Grieg-Smith (1952) employed a nested (hierarchical) analysis of variance (ANOVA) to determine spatial scales of pattern for single species populations (the mean square versus block size technique). In this procedure, typical 'patch sizes' would correspond to peak mean square values. In addition, mean square to mean ratios would be analogous to variance to mean ratios, and can be used as a measure of the intensity of pattern (assuming that the Poisson distribution is suitable as a null model). Kershaw (1960) extended Grieg-Smith's (1952) procedure to describe spatial associations between species pairs with the relationship:

$\operatorname{Var}\left(\mathrm{X}_{1}+\mathrm{X}_{2}\right)=\operatorname{Var}\left(\mathrm{X}_{1}\right)+\operatorname{Var}\left(\mathrm{X}_{2}\right)+2 \operatorname{Cov}\left(\mathrm{X}_{1}, \mathrm{X}_{2}\right)$

where $X_{1}$ and $X_{2}=$ abundances of species 1 and 2 ; Var = variance (or mean square in ANOVA); and Cov $=$ covariance. Covariances would be greater than, equal to, or less than zero if species are positively, randomly, or negatively associated, respectively.

Schluter (1984) employed the expanded form of Eq. (1) to determine associations among 3 or more species:

$$
\operatorname{Var}(\mathrm{T})=\sum_{i}^{M} \operatorname{Var}\left(\mathrm{X}_{j}\right)+2 \sum_{i<1}^{M} \operatorname{Cov}\left(\mathrm{X}_{i}, \mathrm{X}_{1}\right)
$$

where $\operatorname{Var}(T)=$ variance of the sample totals (abundance of all species in a sample); $\Sigma \operatorname{Var}\left(\mathrm{X}_{i}\right)=$ the sum of variances of all individual species; $\Sigma \operatorname{Cov}\left(X_{1}, X_{1}\right)=$ the sum of all pairwise covariances between species; and $M=$ the number of species. Schluter (1984) defined the association index, $V$, as the ratio of the sample to (summed) species variances:

$$
V=\operatorname{Var}(\mathrm{T}) / \sum_{i}^{M} \operatorname{Var}\left(\mathrm{X}_{i}\right)
$$

$V$ would equal 1.0 in the case of no net (or random) association among species (e.g. the sum of covariances equals zero). Values greater or less than 1.0 would represent instances of net positive or negative associations, respectively. With the null hypothesis of no net association, $\Sigma \operatorname{Var}\left(\mathrm{X}_{1}\right)$ represents the theoretical (expected) variance, $\sigma^{2}$; and $\operatorname{Var}(T)$, the observed variance, $S^{2}$. Consequently, probabilities can be determined by the $\chi^{2}$ distribution:

$$
\begin{gathered}
\chi_{N-1}^{2}=(N-1)\left(\mathrm{S}^{2} / \mathrm{o}^{2}\right) \\
=(N-1)\left[\operatorname{Var}(\mathrm{T}) / \sum_{1}^{N} \operatorname{Var}\left(\mathrm{X}_{i}\right)\right]=(N-1) V
\end{gathered}
$$

where $N=$ the number of samples. Because variances are usually based on field samples, $(N-1)$ degrees of freedom, and not $N$ as suggested by Schluter (1984), would be more appropriate in the determination of probabilities (note that Eq. [4] is also the basis of Fisher's Index of Dispersion used for testing the significance of variance to mean ratios for the Poisson distribution)

Schluter's (1984) procedure can be easily incorporated into a nested ANOVA format. Table 1 shows that the Within Species terms in a 1-way (Species) ANOVA is composed of the Among Samples and Interaction terms in an unreplicated 2 -way (Species $\times$ Samples) ANOVA. The effect of scale is determined by nesting contiguous quadrats (i.e. following the format of GriegSmith 1952), and analyzing data for each individual species and the sample totals. Interaction terms are obtained by differences between the (total Within) Species and (Among) Samples terms. At each block size, the ratio of the (Among) Samples to (Within) Species mean squares would represent the association index, $V$, and probabilities determined by $\chi^{2}$. (Because of the mechanics of ANOVA, the summation of Species variances in Eq. [3] is not required for the determination of $V$.) If desired, probabilities of species association can also be determined by the $F$ ratio of Among Samples to Interaction mean squares (McCulloch 1985). The mechanics of the methodology are detailed in a hypothetical example in the Appendix.

Field sites. Shallow-water gorgonian communities were examined at 2 sites near La Parguera on the southwest coast of Puerto Rico. Media Luna $\left(17^{\circ} 56.2^{\prime} \mathrm{N}\right.$, $67^{\circ} 3.2^{\prime} \mathrm{W}$ ) is a low relief reef at a depth of $6.7 \mathrm{~m}$. San Cristobal $\left(17^{\circ} 55.7^{\prime} \mathrm{N}, 67^{\circ} 4.4^{\prime} \mathrm{W}\right)$ has moderate topographic relief at a depth of $10.6 \mathrm{~m}$. Both sites are exposed to wave action generated by the easterly tradewinds. The sessile fauna is visually dominated by gorgonians at both sites. Substrate cover by corals and sponges is about 25 and $8 \%$ at San Cristobal and Media Luna, respectively ( $\mathrm{V}$. Vicente pers. comm.).

The gorgonian communities at both sites have been monitored in a $1 \times 32 \mathrm{~m}$ transect at 3 to 6 mo intervals since August 1983. Colony locations were determined by placing a $0.5 \mathrm{~m}^{2}(0.5 \times 1.0 \mathrm{~m})$ quadrat subdivided into $1 / 16 \mathrm{~m}^{2}(25 \times 25 \mathrm{~cm})$ areas along the transect. A chain and nails placed at $0.5 \mathrm{~m}$ intervals in the center and both edges of the transect were used to relocate quadrats between surveys. Replicate surveys indicated that estimates of colony location usually differed less than $10 \mathrm{~cm}$.

Gorgonians were identified by field characteristics, 
Table 1. Relationship between a 1-way (Species) to an unreplicated 2-way (Species and Samples) analysis of variance. $M$ : number of species; $N$ : number of samples

\begin{tabular}{|c|c|c|c|}
\hline Source & SS & $d f$ & MS \\
\hline Among Species & SS (Among Species) & $M-1$ & SS (Among Species)/(M-1) \\
\hline Within Species & SS (Within Species) & $M(N-1)$ & SS (Within Species) $/ M(N-1)$ \\
\hline Among Samples & SS (Among Samples) & N-1 & $\mathrm{SS}$ (Among Samples) $/(N-1)$ \\
\hline Interaction & SS (Interaction) & $(N-1)(M-1)$ & SS (Interaction) $/(N-1)(M-1)$ \\
\hline Total & SS (Total) & $M N-1$ & \\
\hline
\end{tabular}

although identifications of larger colonies $(\geq 25 \mathrm{~cm}$ in height) were verified by spicule preparations (following Bayer 1961) from branch tip samples. However, variations in spicule and colony characteristics made identification to the species level difficult for several taxa. In addition, species-specific spicule characteristics of newly-recruited colonies (usually $<5 \mathrm{~cm}$ in height) are often undeveloped. Consequently, we used the lowest feasible taxonomic categories for data analysis. Fortunately, this procedure is conservative with respect to the major conclusions of this study (see 'Discussion').

The smallest (unit) quadrat size examined in the analysis of spatial pattern was $1 / 64 \mathrm{~m}^{2}(12.5 \times 12.5 \mathrm{~cm})$, based largely on estimates of measurement error. Contiguous quadrats were then nested in multiples of 2 within each $\mathrm{m}^{2}$ following the grid (2-dimensional) design of Grieg-Smith (1952). Each $\mathrm{m}^{2}$ was then blocked in multiples of 2 corresponding to the transect (1-dimensional) design of Kershaw (1960). This nesting design was employed to examine pattern on as large a range of spatial scales as possible. Only survey data from the fall of 1986 are analyzed in this report.

\section{RESULTS}

A total of 2436 and 2778 colonies in 19 and 17 taxonomic categories occurred at San Cristobal and Media Luna, respectively (Table 2). Sample and Species mean squares and their ratios, $V$, at various spatial scales are shown in Figs. 1 and 2. In brief, $V$ was significantly greater than 1.0 at all small scales $\left(\leq 1 / 2 \mathrm{~m}^{2}\right)$ at both sites, indicating a positive association among gorgonian species. Significant positive associations also occurred at the 1 and $2 \mathrm{~m}^{2}$ at San Cristobal, and at the $2 \mathrm{~m}^{2}$ at Media Luna. Non-significant (random) associations occurred at all other scales. Patterns

Table 2. Taxonomic groups and colony abundances (in $\left.32 \mathrm{~m}^{2}\right)$ at the study sites. Variance to mean ratios $\left(\mathrm{S}^{2} / \overline{\mathrm{x}}\right)$ are based on $1 / 64$ $\mathrm{m}^{2}$ quadrats. $p \leqslant 0.05 ; \cdots p \leqslant 0.01 ;$ NS: not significant; degrees of freedom $=1024$

\begin{tabular}{|c|c|c|c|c|}
\hline \multirow[t]{2}{*}{ Taxon } & \multicolumn{2}{|c|}{ San Cristobal } & \multicolumn{2}{|c|}{ Media Luna } \\
\hline & No. colonies & $S / \bar{x}$ & No. colonies & $S / \bar{x}$ \\
\hline Pseudopterogorgia spp. & 609 & $1.27^{\cdots}$ & 1177 & $1.57^{\cdots} \cdot$ \\
\hline Pseudoplexaura spp. & 487 & $1.47^{\cdots}$ & 396 & $1.37^{\cdots}$ \\
\hline Eunicea calyculata - E. tourneforti & 231 & $1.20^{\cdots}$ & 459 & $0.92 \mathrm{NS}$ \\
\hline Eunicea laxispica - E. succinea & 194 & $1.28^{\cdots}$ & 130 & $0.91 \mathrm{NS}$ \\
\hline Gorgonia ventalina & 188 & $1.30^{\cdots}$ & 113 & $1.20^{\cdots}$ \\
\hline Plexaura flexuosa & 159 & $1.09^{\circ}$ & 107 & $1.22 \cdots$ \\
\hline Plexaura homomalla f. kukenthalli & 131 & $1.25^{\cdots}$ & 25 & $1.09^{\circ}$ \\
\hline Muricea elongata - $M$. muricata & 80 & $0.96 \mathrm{NS}$ & 113 & $1.36^{\cdots}$ \\
\hline Eunicea sp. 7 & 71 & $1.80^{\circ}$ & 6 & - \\
\hline Muriceopsis flavida & 68 & $1.22^{\cdots}$ & 23 & - \\
\hline Plexaurella spp. & 63 & $1.13^{*}$ & 98 & $1.08^{\circ}$ \\
\hline Plexaura homomalla & 53 & $1.09^{\circ}$ & 17 & - \\
\hline Eunicea spp. & 38 & $1.16^{\cdots}$ & 73 & $1.13^{\cdots}$ \\
\hline Eunicea laciniata & 35 & $0.94 \mathrm{NS}$ & 19 & - \\
\hline Briareum asbestinum & 16 & - & 9 & - \\
\hline Eunicea fusca & 5 & - & 1 & - \\
\hline Eunicea sp. 2 & 4 & - & 0 & - \\
\hline Pterogorgia anceps & 3 & - & 12 & - \\
\hline Eunicea knightii & 1 & - & 0 & - \\
\hline Total & $\overline{2436}$ & & $\overline{2778}$ & \\
\hline
\end{tabular}




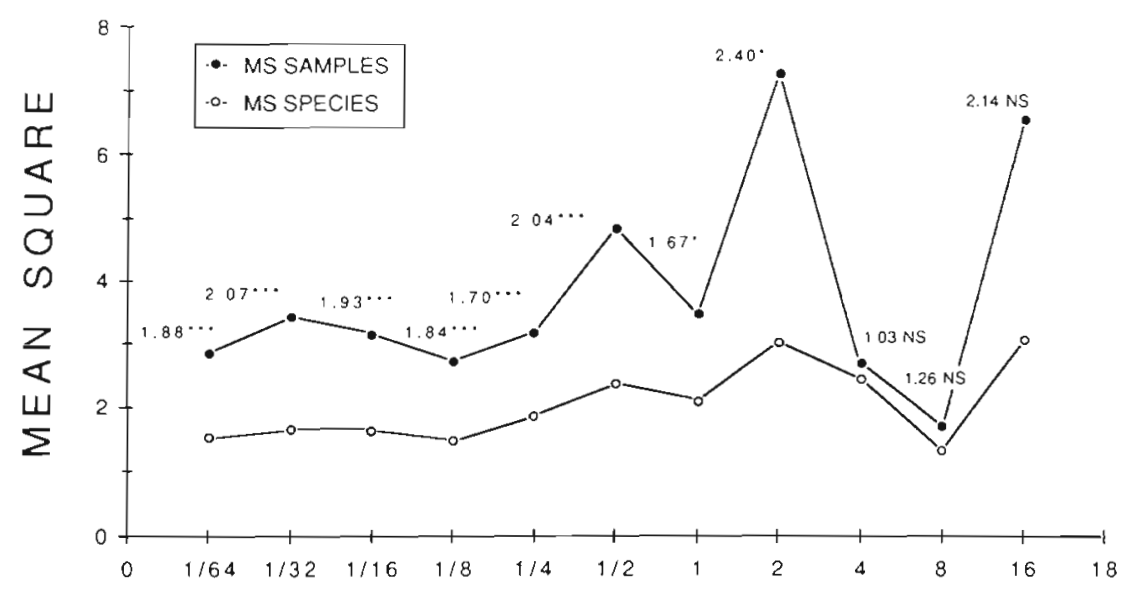

BLOCK SIZE (m2)

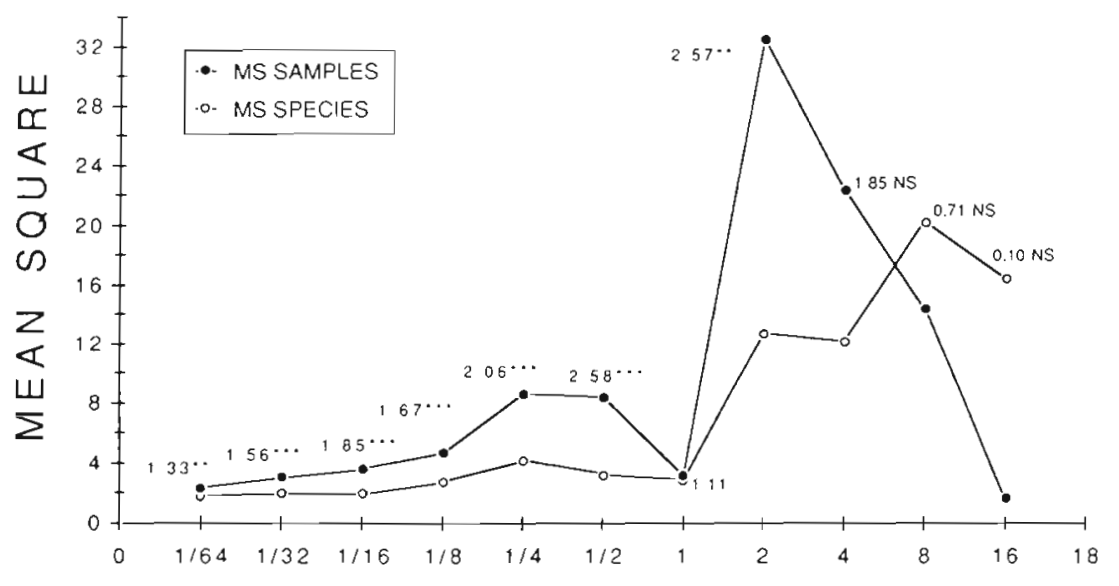

BLOCK SIZE (m2)
Fig. 1. Mean square versus block size of samples and species at the San Cristobal site. Numbers represent $V$, the Samples/ Species mean square ratios. $\cdots p \leq$ $0.001 ; \cdots p \leq 0.01 ; \cdot p \leq 0.05 ;$ NS: not significant
Fig. 2. Mean square versus block size at the Media Luna site. Legend as in Fig. 1

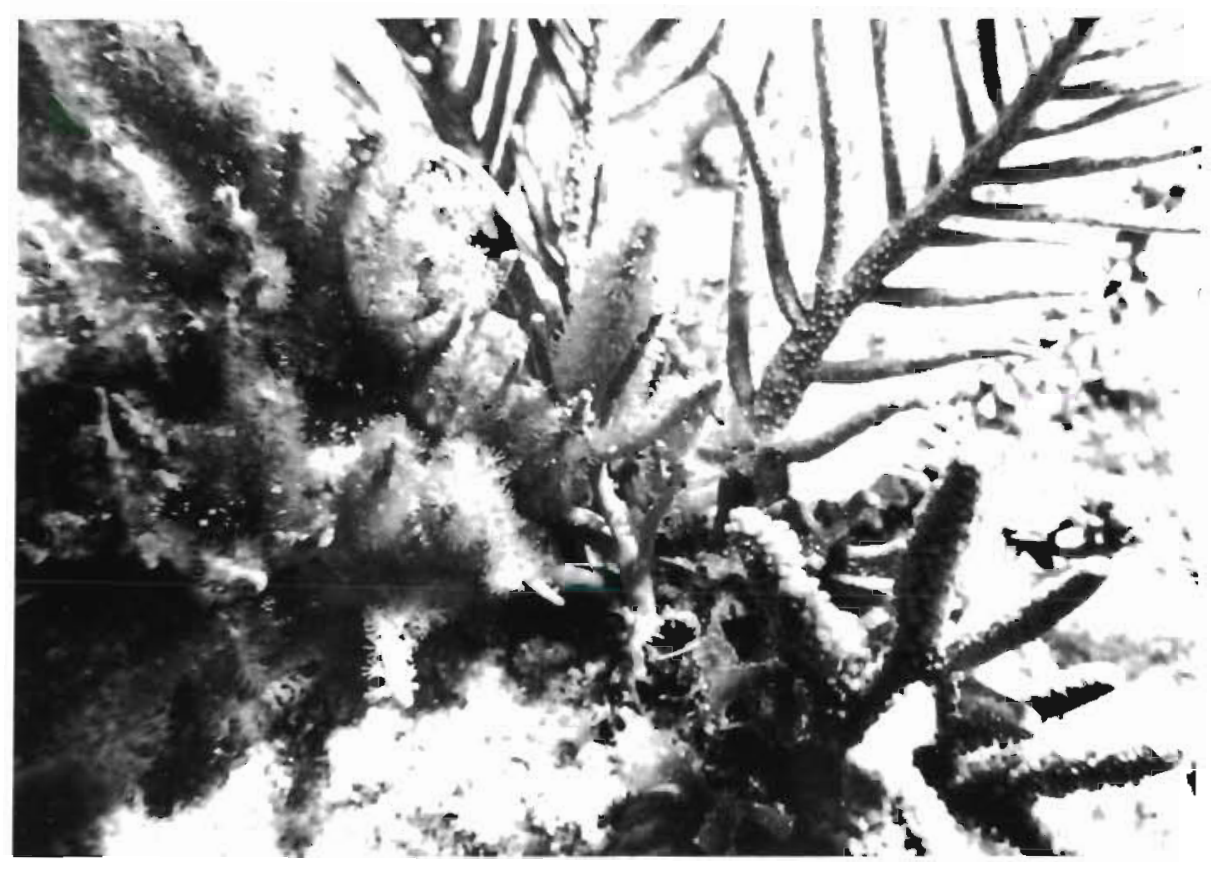

Fig. 3. A 'microscale' (ca $1 / 64 \mathrm{~m}^{2}$ ) patch of colonies. Taxa present include Eunicea, Muriceopsis, Plexaurella, and Plexausa. Colonies are about $10 \mathrm{~cm}$ tall 
at the largest scales were difficult to interpret because of the low degrees of freedom involved.

Peaks of sample mean squares (assessed visually) occurred at the $2 \mathrm{~m}^{2}$ at both sites, and possibly at the $1 / 4$ and $1 / 2 \mathrm{~m}^{2}$ scale at Media Luna and San Cristobal, respectively. Following the interpretation of GriegSmith (1983), these peaks would correspond to the predominant 'patch size' (mosaic scale) of gorgonian colonies. In turn, the positive association among species at these scales indicates that these patches are composed of mixed species assemblages.

Because conditions of the Poisson distribution are easily fulfilled in this study (i.e. the actual substrate space occupied by colony bases is small, and large numbers of colonies can potentially occur in even the smallest spatial scale examined), variance (mean square) to mean ratios can be used to determine additional aspects of pattern. For instance, variance/mean ratios of the sample totals were significantly greater than 1.0 at the $1 / 64 \mathrm{~m}^{2}$ scale at both sites indicating that colonies are aggregated on this scale. Individual taxa displayed a similar pattern; 12 (ex 14) and 8 (ex 10) of the more abundant taxa ( $\geq 25$ colonies per $32 \mathrm{~m}^{2}$ ) were also aggregated at this scale at San Cristobal and Media Luna, respectively (Table 2). Random patterns which were observed for the remaining taxa may arise from the difficulty in determining pattern when abundances are extremely low (Grieg-Smith 1983). Thus, the positive association among species coupled with the aggregated pattern of individual species indicate that aggregations of colonies observed at the smallest spatial scale examined are composed of co-occurring aggregations of individual species. An example of a small-scale, multispecies aggregation is illustrated in Fig. 3. In turn, following the interpretation of GriegSmith (1983), the general increase in sample mean squares observed with increasing spatial scale at both sites indicates that these multispecies aggregations are themselves aggregated until the mosaic scale of about $1 / 4$ and $2 \mathrm{~m}^{2}$ is reached.

\section{DISCUSSION}

The patterns revealed in this study provide several major inferences about the ecology of shallow-water gorgonian communities in Puerto Rico. Following the reasoning of Grieg-Smith (1983), the observed patch sizes of $1 / 4$ to $1 / 2$ and $2 \mathrm{~m}^{2}$ represent the spatial scales at which the major ecological process controlling shallowwater gorgonian communities are most fully developed. Visual inspections of the habitat suggest that patch sizes correspond to the predominant scales of topographic elevations. Variations in topography may be relatively small, often involving differences in relief of only a few centimeters. However, their effects on gorgonian abundances can be dramatic (Fig. 4). In a complementary study, a multivariate ordination analysis of gorgonians sampled from various areas around Puerto Rico indicates that sediment transport is the major factor controlling the large-scale (regional) distribution of gorgonians (Yoshioka \& Yoshioka unpubl.). The
Fig. 4. A small-scale (ca $1 / 4 \mathrm{~m}^{2}$ ) patch of colonies on a low relief topographic elevation. Taxa present include Gorgonia, Eunicea, Pseudopterogorgia, and Pseudoplexaura. Most colonies are between 10 and $20 \mathrm{~cm}$ tall

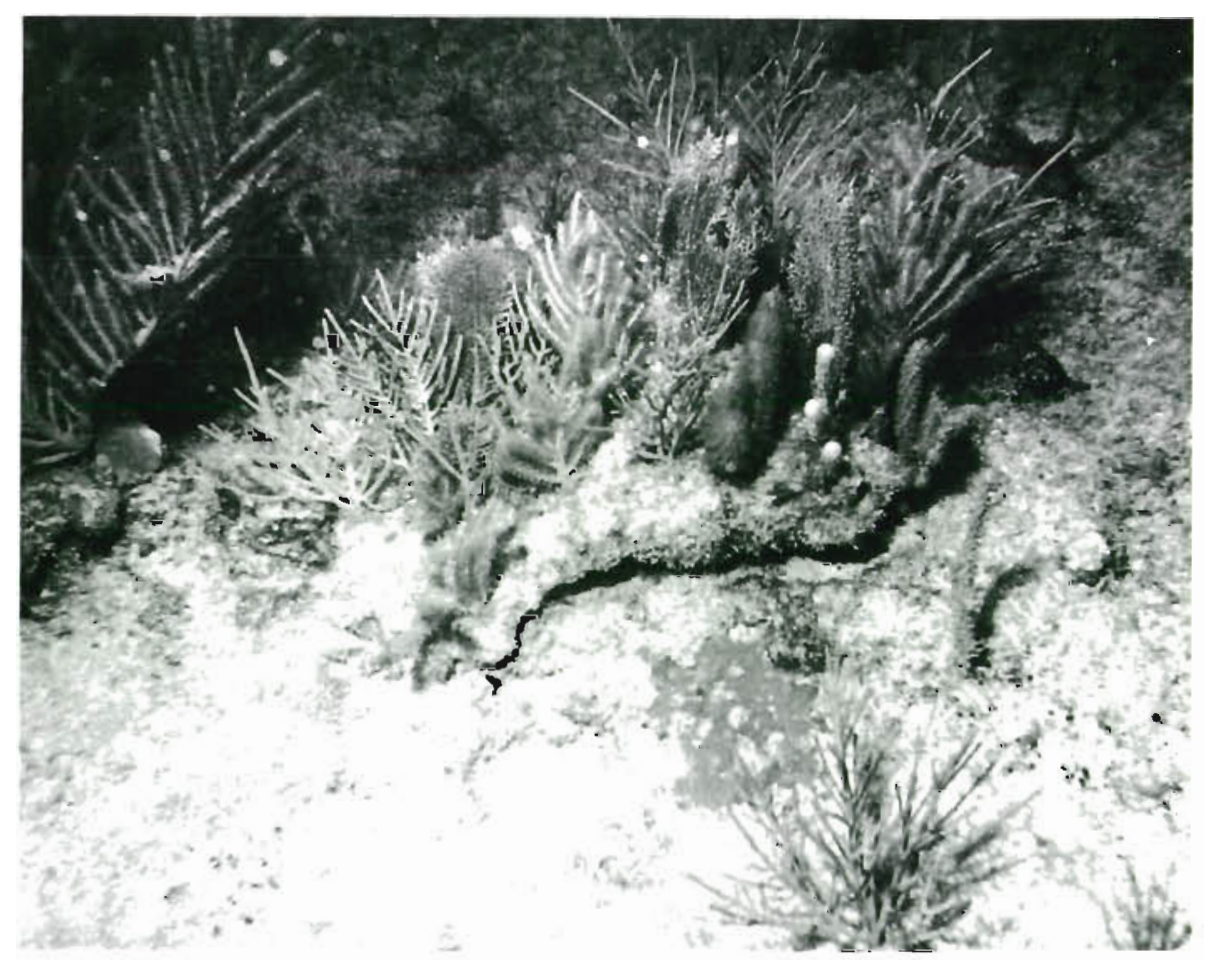


combined results of both studies suggest that variation in sediment transport due to local topography is the major factor underlying the spatial mosaic of gorgonian communities.

The positive association among species on smaller $\left(<1 / 2 \mathrm{~m}^{2}\right)$ spatial scales also indicates that gorgonians, in general, react similarly to small scale features of their habitat. In other words, a given location would be favorable (or unfavorable) for all gorgonians regardless of the species involved. The resultant emphasis on ecological similarities among species corresponds with Sale's (1977) view of coral reef fish communities. In contrast, these patterns contradict predictions of a negative association among species derived from resource partitioning theory (MacArthur 1972, Schoener 1974), and thereby suggest that competition for spatial resources has not played a dominant role in the evolution of gorgonian communities. Dana (1976) reached a similar conclusion based on spatial associations among scleractinian corals in Panama.

Although these results do not necessarily disprove the existence of competition among gorgonians, additional information from the literature suggests that competitive interactions for space (if present) are over- shadowed by beneficial effects arising from predatorprey relationships. All known gorgonian predators, such as the polychaete Hermodice carunculata, the gastropod Cyphoma gibbosum, and the fish Chaetodon capistratus (Lasker 1985, Wahle 1985, Harvell \& Suchanek 1987, Lasker \& Coffroth 1988), are commonly described as 'partial predators' which are incapable of consuming entire colonies. Bertram (1978) has suggested that small-scale aggregations of prey would 'dilute' the effects of such predators on individuals. Pawlik et al. (1987) among others, have documented the presence of chemical defenses in gorgonians. In an analogous terrestrial example, Sillen-Tullberg \& Leimar (1988) have found that 'distasteful' insects can reduce the effects of predation by occurring in aggregations. Also, Hay (1986) and Littler et al. (1987) have demonstrated that spatial associations result in mutualistic effects in algal and gorgonian-algal communities with chemically-defended species.

Acknowledgements. This paper is dedicated to the late E. W Fager who introduced one of us (P. M. Y.) to the analysis of spatial patterns. Preliminary drafts of the manuscript were reviewed by $C$. Goenaga and V. Vicente. Support for field research was provided the Office of Research Coordination of the University of Puerto Rico, Mayaguez.

Appendix. A hypothetical example of the analysis involving 4 species in a 32 unit long transect. Initial abundances were based on random numbers from 0 to 9 and patches (in boldface) were generated by adding 10 to the original values. The example illustrates the case where patch size of individual species are 2 units long and contiguous (non-overlapping) in Quadrats 3 to 10 and 24 to 31 , thereby resulting in Sample patches of 8 units. Thus, peak mean squares should occur at the pairs level for Species and octet level for Samples with a negative and positive association among species at these scales, respectively

$$
\begin{aligned}
& \begin{array}{llllllllllllllllllllllllllllllllll}
\text { Quadrat no. } & 1 & 2 & 3 & 4 & 5 & 6 & 7 & 8 & 9 & 10 & 11 & 12 & 13 & 14 & 15 & 16 & 17 & 18 & 19 & 20 & 21 & 22 & 23 & 24 & 25 & 26 & 27 & 28 & 29 & 30 & 31 & 32 & \text { Total }
\end{array} \\
& \begin{array}{lllllllllllllllllllllllllllllllllllll}
\text { Species } & A & 2 & 9 & 14 & 16 & 9 & 4 & 7 & 4 & 5 & 7 & 5 & 9 & 5 & 4 & 6 & 0 & 4 & 0 & 9 & 5 & 7 & 4 & 0 & 1 & 7 & 5 & 5 & 16 & 14 & 1 & 5 & 1 & 190
\end{array} \\
& \begin{array}{llllllllllllllllllllllllllllllllllllll}
\text { Species } & B & 8 & 9 & 3 & 2 & 14 & 16 & 7 & 2 & 2 & 8 & 6 & 4 & 1 & 4 & 8 & 3 & 1 & 3 & 3 & 1 & 0 & 0 & 9 & 18 & 16 & 3 & 3 & 7 & 7 & 5 & 7 & 8 & 188
\end{array} \\
& \begin{array}{llllllllllllllllllllllllllllllllllllll}
\text { Species } & C & 3 & 5 & 8 & 5 & 3 & 4 & 5 & 7 & 15 & 10 & 1 & 6 & 7 & 2 & 5 & 0 & 6 & 8 & 2 & 2 & 9 & 2 & 3 & 3 & 6 & 9 & 3 & 4 & 6 & 12 & 10 & 2 & 173
\end{array}
\end{aligned}
$$

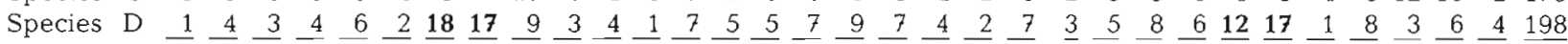

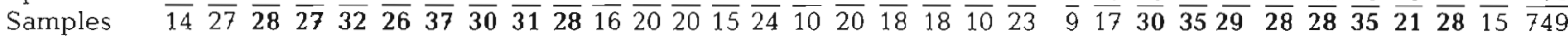

$$
\begin{aligned}
& \text { Mechanics of a hierarchical ANOVA in which quadrats are nested in multiples of } 2 \text { would be as follows for Species A: } \\
& \sum \frac{\text { (units) })^{2}}{\mathrm{bs}_{1}}=\frac{(2)^{2}}{1}+\frac{(9)^{2}}{1}+\frac{(14)^{2}}{1}+\ldots+\frac{(1)^{2}}{1}=1722 \\
& \Sigma \frac{(\text { pairs })^{2}}{b_{2}}=\frac{(2+9)^{2}}{2}+\frac{(14+16)^{2}}{2}+\ldots+\frac{(5+1)^{2}}{2}=1474 \\
& \sum \frac{{\text { (quartets })^{2}}_{\mathrm{bs}_{4}}}{4}=\frac{(2+9+14+16)^{2}}{4}+\ldots+\frac{(14+1+5+1)^{2}}{4}=1289 \\
& \sum \frac{\left.\sum \text { octets }\right)^{2}}{b s_{8}}=\frac{(2+9+14+\ldots+4)^{2}}{8}+\ldots+\frac{(7+5+5+\ldots+1)^{2}}{8}=1215.25 \\
& \frac{\Sigma\left(16^{\prime} s\right)^{2}}{\mathrm{bs}_{16}}=\frac{(2+9+14+\ldots+0)^{2}}{16}+\ldots+\frac{(4+0+9+\ldots 1)^{2}}{16}=1143.25 \\
& \frac{\Sigma(32 \mathrm{~s})^{2}}{\mathrm{bs}_{32}}=\frac{(2+9+14+\ldots+1)^{2}}{32}=\frac{(190)^{2}}{32}=1128.125 \\
& \mathrm{SS}_{\text {units }}=1722-1474=248.0: \mathrm{df}=16 \\
& \mathrm{SS}_{\text {paits }}=1474-1289=185.0 ; \mathrm{df}=8 \\
& \mathrm{SS}_{\text {quart }}=1289-1215.25=73.75 ; \mathrm{df}=4 \\
& \mathrm{SS}_{\text {oct }}=1215.25-1143.25=72.0 ; \mathrm{df}=2 \\
& \mathrm{SS}_{16 \mathrm{~s}}=1143.25-1128.125=15.125 ; \mathrm{df}=1
\end{aligned}
$$


Appendix (cont.)

The Sums of Squares for (Total Within) Species and Samples would be as follows. (Note that a correction for the number of species in used in ANOVA for the calculation of the Samples Sums of Squares)

\begin{tabular}{|c|c|c|c|c|c|c|c|c|c|c|}
\hline & \multicolumn{2}{|c|}{ Units } & \multicolumn{2}{|c|}{ Pairs } & \multicolumn{2}{|c|}{ Quartets } & \multicolumn{2}{|c|}{ Octets } & \multicolumn{2}{|c|}{ Sixteens } \\
\hline & $\mathrm{df}$ & SS & df & SS & $\mathrm{dt}$ & SS & df & SS & df & SS \\
\hline Species A & 16 & 248.0 & 8 & 185.0 & 4 & 73.75 & 2 & 72.0 & 1 & 15.125 \\
\hline Species B & 16 & 192.0 & 8 & 360.0 & 4 & 83.75 & 2 & 66.625 & 1 & 1.125 \\
\hline Species C & 16 & 140.5 & 8 & 153.75 & 4 & 49.125 & 2 & 20.312 & 1 & 0.031 \\
\hline Species D & $\underline{16}$ & 217.0 & 8 & $\underline{233.0}$ & $\underline{4}$ & $\underline{152.50}$ & $\underline{2}$ & 21.25 & $\underline{1}$ & 1.125 \\
\hline Total Within Species & $\overline{64}$ & $\overline{797.5}$ & $\overline{32}$ & $\overline{921.75}$ & $1 \overline{6}$ & $\overline{361.125}$ & $\overline{8}$ & 180.188 & $\overline{4}$ & 17.406 \\
\hline Samples & 16 & 166.875 & 8 & 85.313 & 4 & 66.469 & 2 & 136.328 & 1 & 3.445 \\
\hline
\end{tabular}

The ANOVA table. Peak mean squares (in boldface) occur at the pairs and octets levels for Species and Samples with a significant negative and positive association among species at these scales, respectively. Note that an ANOVA without reference to scale (Totals near bottom of table) indicates an overall nonsignificant association among species. $V$ : Samples/Species mean square ratios: ${ }^{\cdot} p<0.05$ (positive association); ${ }^{\circ} p>0.95$ (negative association); NS: not significant

\begin{tabular}{|c|c|c|c|c|}
\hline Source & df & SS & MS & \\
\hline Among Species & 3 & 10.211 & 3.403 & \\
\hline \multicolumn{5}{|l|}{ Within Species } \\
\hline \multicolumn{5}{|l|}{ Among Units: } \\
\hline Samples & 16 & 166.875 & 10.430 & $F_{16,48}=0.79 \mathrm{NS}$ \\
\hline Interaction & 48 & 630.625 & 13.138 & \\
\hline Species & $\frac{7}{64}$ & 797.500 & 12.461 & $V=0.84 \mathrm{NS}$ \\
\hline \multicolumn{5}{|l|}{ Among Pairs: } \\
\hline Samples & 8 & 85.313 & 10.664 & $F_{8.24}=0.306^{\circ}$ \\
\hline Interaction & 24 & 836.437 & 34.851 & \\
\hline Species & $\frac{-2}{32}$ & 921.750 & 28.805 & $V=0.370^{\circ}$ \\
\hline \multicolumn{5}{|l|}{ Among Quartets: } \\
\hline Samples & 4 & 66.469 & 16.617 & $F_{4,12}=0.677 \mathrm{NS}$ \\
\hline Interaction & 12 & 294.686 & 24.557 & \\
\hline Species & $\frac{2 .}{16}$ & 361.125 & 22.570 & $V=0.736 \mathrm{NS}$ \\
\hline \multicolumn{5}{|l|}{ Among Octets: } \\
\hline Samples & 2 & 136.328 & 68.164 & $F_{2,6}=9.325^{\circ}$ \\
\hline Interaction & 6 & 43.859 & 7.310 & \\
\hline Species & $\frac{0}{8}$ & 180.188 & 22.523 & $V=3.026^{\circ}$ \\
\hline \multicolumn{5}{|l|}{ Among Sixteens: } \\
\hline Samples & 1 & 3.445 & 3.445 & $F_{1.3}=0.740 \mathrm{NS}$ \\
\hline Interaction & 3 & 13.961 & 4.654 & \\
\hline Species & $\frac{5}{4}$ & $\frac{1}{17.406}$ & 4.352 & $V=0.792 \mathrm{NS}$ \\
\hline Total Among Samples & 31 & 458.43 & 14.788 & $F_{31,93}=0.757 \mathrm{NS}$ \\
\hline Total Interaction & 93 & 1819.538 & 19.56 & \\
\hline Total Within Species & $1 \overline{24}$ & $2 \overline{277.969}$ & 18.370 & $V=0.805 \mathrm{NS}$ \\
\hline GRAND TOTAL & 127 & 2288.180 & & \\
\hline
\end{tabular}

\section{LITERATURE CITED}

Bayer, F. M. (1961). The shallow-water octocorallia of the West Indian region. Martinus Nijhoff, The Hague

Bertram, B. C. R. (1978). Living in groups: predators and prey. In: Krebs, J. R., Davies, N. B. (eds.) Behavioral ecology: an evolutionary approach. Sinauer, Sunderland, p. 64-96

Connell, J. H. (1978). Diversity in tropical rain forests and coral reefs. Science 199: 1302-1310

Dana, T. F. (1976). Reef-coral dispersion patterns and environmental variables on a Caribbean coral reef. Bull. mar. Sci. 26: $1-13$
Dayton, P. K., Currie, V., Gerrodette, T., Keller, B. D., Rosenthal, R., Ven Tresca, D. (1984). Patch dynamics and stability of some California kelp communities. Ecol. Monogr. 54: 251-289

DeAngelis, D. L., Waterhouse, J. C. (1987). Equilibrium and nonequilibrium concepts in ecological models. Ecol. Monogr. 57: 1-21

Diggle, P. J. (1983). Statistical analyses of spatial point patterns. Academic Press, New York

Grieg-Smith, P. (1952). The use of random and contiguous quadrats in the study of the structure of plant communities. Ann. Bot. 16: 293-316 
Grieg-Smith, P. (1983). Quantitative plant ecology. University of California Press, Berkeley

Harvell, C. D., Suchanek, T. H. (1987). Partial predation on tropical gorgonians by Cyphoma gibbosun (Gastropoda). Mar. Ecol. Prog. Ser. 38: 37-44

Hay, N. E. (1986). Associational plant defenses and the maintenance of species diversity: turning competitors into accomplices. Am. Nat. 128:617-641

Hubbell, S. P. (1979). Tree dispersion, abundance, and diversity in a tropical dry forest. Science 203: 1299-1309

Hutchinson, G. E. (1953). The concept of pattern in ecology. Proc. natn. Acad. Sci. U.S.A. 105: 1-12

Jackson, J. B. C. (1977). Competition on marine hard substrata: the adaptive significance of solitary and colonial strategies. Am. Nat. 111: 743-767

Jackson, J. B. C. (1979). Overgrowth competition between encrusting cheilostome ectoprocts in a Jamaican cryptic reef environment. J. Anim. Ecol, 48: 805-823

Jumars, P. A. (1975a). Methods for measurement of community structure in deep-sea macrobenthos. Mar. Biol. 30: 245-252

Jumars, P. A. (1975b). Environmental grain and polychaete species diversity in a bathyal benthic community. Mar. Biol. 30: 253-266

Kershaw, K. A. (1960). The detection of pattern and association. J. Ecol. 48: 233-242

Lasker, H. R. (1985). Prey preferences and browsing pressure of the butterflyfish Chaetodon capistratus on Caribbean gorgonians. Mar. Ecol. Prog. Ser 21: 213-220

Lasker, H. R., Coffroth, M. A. (1988). Temporal and spatial variability among grazers: variability in the distribution of the gastropod Cyphoma gibbosum on octocorals. Mar. Ecol. Prog. Ser. 43: 285-295

This article was submitted to the editor
Littler, M. M., Littler, D. S., Taylor, P. R. (1987). Animal-plant defense associations: effects on the distribution and abundance of tropical reef macrophytes. J. exp. mar Biol. Ecol. 105: 107-121

MacArthur, R. H. (1972). Geographical ecology. Harper and Row, Princeton, New Jersey

McCulloch, C. F. (1985). Variance test for species association. Ecology 66: 1676-1681

Pawlik, J. R., Burch, M. T., Fenical, W. (1987). Patterns of chemical defense among Caribbean gorgonian corals: a preliminary survey. J. exp. mar. Biol. Ecol. 108: 55-66

Sale, P. F. (1977). Maintenance of high diversity in coral reef fish communities. Am. Nat. 111: 337-359

Schluter, D. (1984). A variance test for detecting species associations, with some example applications. Ecology 65: 998-1005

Schoener, T W (1974). Resource partitioning in ecological communities. Science 185: 27-39

Sillen-Tullberg, B., Leimar, O. (1988). The evolution of gregariousness in distasteful insects as a defense against predators. Am. Nat. 132: 723-734

Wahle, C. M. (1985). Habitat-related patterns of injury and mortality among Jamaican gorgonians. Bull. mar. Sci. 37 905-927

Woodley, J. D., Chornesky, E. A., Clifford, A. A., Jackson, J. B. C., Kaufman, L. S., Knowlton, N., Lang, J. C., Pearson, M. P., Porter, J. W., Rooney, M. C., Rylaarsdam, K. W., Tunnicliffe, V. J, Wahle, C. M., Wulff, J. L., Curtis, A. S. G., Dallmeyer, M. D., Jupp, B. P., Koehl, M. A. R., Niegel, J., Sides, E. M. (1981). Hurricane Allen's impact on Jamaican coral reefs. Science $214: 749-755$

Manuscript first received: October 17, 1988

Revised version accepted: April 5, 1989 